\title{
Towards a model of the syntax-discourse interface: a syntactic analysis of please ${ }^{1}$ REBECCA WOODS \\ Newcastle University
}

\footnotetext{
${ }^{1}$ This article has been many years and many revisions in the making. The first iteration was produced during my ESRC 1+3 scholarship number ES/J500215/1 at the University of York. Thanks to colleagues and visitors at the University of York, in particular
} George Tsoulas, Norman Yeo, Maria-Margarita Makri, Elin McCready and Eytan Zweig, and the audience at ConSOLE XXIII (7-9 January 2015) in Paris, in particular Jon Ander Mendia, Imke Driemel, Andrew Murphy and Victor Pan, as well as two anonymous reviewers for Proceedings of ConSOLE XXIII, where an earlier version of this article appeared. The second iteration was submitted for the ISLE Richard M. Hogg Prize in 2017—my thanks to the prize committee for their feedback, in particular Martin Hilpert and David Denison. This third iteration owes much to two anonymous reviewers for their time and extensive comments and suggestions, as well as the help and patience of ELL editor Bernd Kortmann and secretary Melitta Cocan, as it turns out that the gestation of a child (and subsequent period of parental leave) is much shorter than that of (some) research ideas. All remaining errors are my own. The work is dedicated to the memory of the 17 people killed in the 2015 Paris terror attacks, which coincided with ConSOLE XXIII. 


\begin{abstract}
This paper examines the syntax and semantics of please. Using a mainstream generative syntactic framework, I propose that syntactically integrated please is a discourse marker that marks the clause in which it occurs as a request. Please may appear clause-initially or clause-medially as determined by a number of factors, including clause type, modality, negation and the application of ellipsis. There is also a homophonous marker please that occurs in clause-final position; clause-final please does not mark requests per se but 'bonds' a speaker and addressee, reinforcing their relationship as requester and requestee. This analysis of please provides support for syntactic approaches to speech act structure, particularly the claim that illocutionary force is part of narrow syntax rather than a solely pragmatic phenomenon. The paper provides support for pursuing a model of the syntax-discourse interface in which interactions between discourse markers and clause-internal functional elements, such as mood and modality, form the interface between syntax and discourse.
\end{abstract}

Keywords: Syntax-discourse interface, speech acts, discourse particles 


\section{INTRODUCTION}

Syntactic speech act theory is undergoing a productive revival. Where illocutionary force was previously the domain of scholars of philosophy and pragmatics, syntacticians such as Speas \& Tenny (2003), Hill (2007a, b, 2014), and Wiltschko \& Heim (2016) have advanced convincing claims that syntax includes some limited information about illocutionary force and the intentions and perspectives of the discourse participants.

Illocutionary force is a notoriously slippery concept to define. For the purposes of this article I follow Krifka (2014) in claiming that illocutionary force expresses information about discourse participants and their commitment to the property or proposition(s). That may be a commitment to the truth of a proposition, an expectation to provide an answer, or an expectation to enact some action, to name a few. In this article I show that illocutionary force is distinct from clause type despite an intimate link between the two, because the distribution of syntactic expressions of illocutionary force cross-cuts clause types. Moreover, though expressions of illocutionary force do not affect the truth conditions of an utterance, they impact upon grammaticality and felicity in context.

If illocutionary force is present in syntax, there should be overt evidence for its presence. In this article, I examine a candidate for the overt spell-out of illocutionary force in English, namely please. Please has been variously analysed as an adverbial (e.g. Sadock 1974), a discourse marker (e.g. Biber et al 1999), and a politeness marker (e.g. Stubbs 1983). The latter scholars in particular assert that please is independent of syntax and "only marginally [...] a syntactic item at all" (Stubbs 1983: 71). In this paper I will contest this characterisation of please and build on House's (1989) pragmatically 
motivated analysis of please as a request marker. I claim that, based on distribution, compatibility with different clause types, and the interpretations that result, syntactically integrated please is an overt realisation of a syntactic head. This head encodes information about the illocutionary act $^{2}$ expressed by the utterance. In doing this, I also build on work in pragmatics by Wichmann (2004) and Sato (2008), both of whom claim that the clausal position of please impacts on its use and interpretation. Wichmann also considers the prosody of please, but other factors restricting the availability of please, such as clause type, are not delved into. I will present a corpus study of please and its distribution along with other syntactic and semantic data points both attested and constructed. In short, please's use and meaning has been much studied, but its tightly constrained syntactic behaviour has not yet been examined in this level of detail. My primary claim is that clause-initial (henceforth initial) please is an illocutionary act head marking requests. Such an account derives initial please's restriction to imperative and polar interrogative clause types, as well as the obligatory interpretation of the clause containing it as a request. I discuss a variant of initial please - medial please - which has a broader distribution but is still constrained by syntactic factors including the relative positions of modality and negation. I also account for final please, analysing it too as a high functional head that relates obliquely to requesting. Final please differs from initial please in crucial and interesting ways that

\footnotetext{
2 I use Krifka's (2014) 'illocutionary act' terminology rather than Speas \& Tenny's (2003) 'speech act' terminology because there are elements of the interpretation of speech acts that are outside of syntax and to distinguish between 'embedded root' and true root phenomena. See Krifka (2014) and Woods (2016a, b) for more details.
} 
lead to a broader distribution even than medial please. ${ }^{3}$ I will not, in this paper, address please's relationship to politeness and face, as this concerns the pragmatic level exclusively and has been extensively studied by theorists in these areas (see Sato 2008, Aijmer 2015 for recent approaches). Along the way I examine the consequences of this work for syntactic speech act theory and draw together different approaches to the array of projections above IP.

For clarity, I lay out here my definition of the illocutionary act of requesting. Requesting illocutionary acts are direct acts made by the speaker. Such an act consists of an utterance through which the speaker expresses a requirement for the addressee to commit to act in a specified way. Imperatives, part of Searle's (1979) class of 'directives', canonically form requesting illocutionary acts, but not all directives do; while Searle includes all types of interrogative in this class, not all types of interrogatives can be requests. As Sadock (1974) notes, where some interrogatives may be interpreted as either information-seeking questions or requests, others may only be interpreted as information-seeking questions. At first blush, the definition above does not account for this difference; arguably, information-seeking questions are a subset of requests in which the specific act required by the addressee is the proffering of an answer. Empirically, however, (non-overtly-marked) requests with interrogative syntax may have an information-seeking question interpretation as well, while the reverse does not hold: polar questions can be requests or information-seeking questions, while wh-

\footnotetext{
${ }^{3}$ An anonymous reviewer notes that the distribution and use of if you please may, like please, vary in interesting ways. A discussion of this construction is not possible in this article for space reasons but would provide a useful future direction for this work. I will also not discuss parenthetical please in this work, not least because I do not possess the knowledge of prosody that I believe is necessary to do that topic justice.
} 
questions and alternative questions (see Bolinger 1978) can only be information-seeking questions.

(1) Can you open the window? means:

a. I request that you open the window.

b. Tell me: are you able to open the window?

(2) Can you open the window or not? means:

a. \#I request that you open the window or that you do not open the window. ${ }^{4}$

b. Tell me: are you able to open the window or are you not able to open the window?

(3) Which window can you open? means:

a. \#I request that you open some window such that you can open that window.

b. Tell me: which is the window such that you can open that window?

Only the polysemous type of question is compatible with please, as (4)-(6) illustrate. ${ }^{5}$

\footnotetext{
${ }^{4}$ All constructed data and native-speaker judgements have been checked with at least six native British English speakers consisting of a mixture of linguists and non-linguists, unless otherwise stated. Particular thanks to six informants from Cheshire, Liverpool and Manchester for their North West English judgements. Judgements are reflected using the following diacritics: * = ungrammatical; \# = infelicitous in the given context; ?/?? = marginally accepted as grammatical, with double ?? marking greater degradation and divergence in informant judgements than single ?; \% = accepted as grammatical in some but not all dialects. The absence of a diacritic indicates grammaticality.

${ }^{5}$ See Blum-Kulka (1985) for experimental results showing this disambiguating effect of please in both Hebrew and English, and House (1989) for similar findings in German, English, and the L2 English of L1 German learners.
} 
(4) a. Can you open the window?

b. Please can you open the window?

(5) a. Can you open the window or not?

b. *Please can you open the window or not?

(6) a. Which window can you open?

b. *Please which window can you open?
Information-seeking or request

Request only

Information-seeking only

Information-seeking only

Notice also that 'yes' and 'no' are felicitous spoken responses to both (4a, b) but 'I don't know' is only felicitous in response to (4a). This test will be of use later in the analysis.

The felicity of a request is also dependent on the propositional arguments.

Compare the following:

(7) Context: You're a teacher and Eskarina and I are your pupils at an after-school tutor session. Our usual fellow pupil, Yasmeen, is not present. We are discussing syntactic theory and the room is very warm. I say to you:

a. (Please) Can you open the window?

b. (Please) Can I open the window?

c. (Please) Can Eskarina open the window?

d. (\#Please) \#Can Yasmeen open the window?

(8) Context: I am an estates manager of an office block; Yasmeen, Eskarina and you share an office. Problems with opening windows have been reported and I'm 
investigating which windows are affected. You're the only member of the office present and I say to you:

a. (Please) Can you open the window?

b. \#(Please) Can I open the window?

c. (\#Please) Can Eskarina open the window?

d. (\#Please) Can Yasmeen open the window?

In (7), the question may only be construed in context as a request, hence (7a-c) are all available and all compatible with initial please. (7d) is infelicitous because Yasmeen is not available to open the window, i.e. to grant the request, and the current discourse context does not support 'Can X open the window?' as an information-seeking question. Conversely, (8a) is felicitous as either an information-seeking question or a request, because either an answer or fulfilment of the request will provide me with the information I need. (8b) is only felicitous as a request, because I cannot expect you to know the answer but if you (can) acquiesce to my request I will gain the relevant information. (8c, d) are infelicitous as requests because Eskarina and Yasmeen are not present, but felicitous as information-seeking questions because information about their ability to open the windows satisfies my conversational goals. We can make the (for now) informal claim that there is a fundamental difference between asking to seek an answer and asking to seek enactment of a specific act.

Indirect requests that make use of context and subtext to form requests, such as the use of 'It's cold in here' to mean 'Close the window', are not classed as requesting illocutionary acts. The machinery required to interpret indirect requests is part of the pragmatic, not syntactic, component. However, these kinds of sentences will not be 
ignored in this paper; instead, the data show that indirect requests are almost never marked with initial please precisely because they cannot be marked with requesting force in the syntax: they are declaratives at the syntactic level and only interpreted as requests at the pragmatic level. Requesting illocutionary acts are therefore utterances through which the speaker overtly expresses that they seek for the relevant actor, who must be present in the discourse, to enact a specific act.

The paper is structured as follows. In section 2 I present the basic paradigm, then I use the International Corpus of English - Great Britain (ICE-GB) to examine the distribution of please in English. I conclude that (a) initial, medial and final please show different distributions across clause types and (b) their distribution cross-cuts clause types. In section 3 I claim that initial please is the overt realisation of a high functional head above the position typically associated with clause-typing and overtly marks the utterance as a request. Medial please is analysed as a phrasal variant of initial please that is dependent on the high functional head lexicalised by initial please. Final please is analysed as a different, higher functional head, whose linearization is due to high leftward movement of the rest of the clause. Section 4 summarises the state of the art of speech act syntax in the light of the preceding analyses. Section 5 concludes.

\section{A SYNTACTIC INVESTIGATION OF PLEASE}

In this section, the distribution of please over clause types is examined using native speaker judgements and the International Corpus of English - Great Britain edition 
(ICE-GB) corpus $^{6}$ (University College London 1998). Other syntactic characteristics of please are also outlined using a mixture of naturalistic data and constructed data checked with native speakers.

All of the data in this section comes from native British English speakers; a range of British, predominantly English, dialects is represented, but as the use of please is not thought to vary by region, this should not affect the comparison across datasets. One exception to this is the embeddability of initial please, which is contingent on an independent dialect feature, namely embedded verb movement; this is discussed in section 2.2.1. The data from ICE-GB is a mixture of writing and spontaneous and planned speech. Instances of the verb please are excluded from the analysis.

\subsection{Distribution of 'please'}

\subsubsection{Canonical positions of 'please'}

While please can appear clause-initially, medially or finally without a prosodic break, there are restrictions on its distribution according to clause type. The basic paradigm is illustrated in examples (9)-(13).

(9) Polar interrogative clauses
a. Please can I have a beer?
b. Can I please have a beer?
c. Can I have a beer please?

\footnotetext{
${ }^{6}$ Wichmann (2004) also uses ICE-GB to study the prosodic qualities of please, but categorises the tokens very differently, making an explicit comparison of our analyses impossible.
} 
(10) Imperative clauses (without an auxiliary)
a. Please get me a beer. ${ }^{7}$
b. Get me a beer please.

(11) Imperative clauses (with an auxiliary)
a. Please do get me a beer.
b. Do please get me a beer.
c. Do get me a beer please.

(12) Declarative clauses
a. *Please I'll have a beer.
b. *I'll please have a beer.
c. I'll have a beer please.

(13) Exclamative clauses ${ }^{8}$
a. *Please what a beer this is!
b. *What a beer this is please!

A study of naturalistic uses of please reveals more detail about its distribution. The ICEGB corpus contains 199 instances of please (excluding uses of the verb to please). The following tables show the distribution of please in different clausal positions and across different clause types ${ }^{9}$. Table 1 shows that initial please is more than twice as common as final please across the ICE-GB corpus and predominates in writing. Final please is in

\footnotetext{
${ }^{7}$ This example is string-ambiguous between initial and medial please; the position of please in imperatives will be taken up in section 3.2.4.

${ }^{8}$ The standalone utterance 'Please!' expressed with a sense of exasperation or disbelief (which might also be transcribed as 'Puh-lease!', see Wichmann 2004: 1540) may seem to be exclamative, but I would claim that this use of standalone please is an imperative in which a structure such as 'spare me' or 'stop now' has been elided; see section 2.1.2. ${ }^{9}$ Annotation for clause type was done by hand by the author. Clause type was determined by classical diagnostics such as verb position and verb mood. Punctuation was not used as a reliable diagnostic particularly because of variation in its use with respect to embedded clauses.
} 
turn twice as common as medial please. However, most examples of final please appear in spoken texts and final position is the most common position for please in spoken texts. $^{10}$

Table 1

Clausal position of 'please' in the ICE-GB corpus

\begin{tabular}{ccc} 
Position & Number of occurrences (in spoken texts) \\
\hline Clause-initial & 114 & $(28)$ \\
\hline Clause-medial & 27 & $(6)$ \\
\hline Clause-final & 50 & $(46)$ \\
\hline Other (e.g. standalone) & 8 & $(6)$ \\
\hline Total & 199 & $(86)$
\end{tabular}

Table 2 shows which types of clause contain please in the ICE-GB corpus. In the spoken texts, please predominantly occurs with the clause types typically used to perform requests, namely interrogatives and imperatives. The written texts show similar figures, though there are fewer interrogatives and fragments in the written texts.

Table 2

Clause types containing 'please' in the ICE-GB corpus

\begin{tabular}{cccc} 
Clause type & $\begin{array}{c}\text { Number of } \\
\text { occurrences } \\
\text { (spoken) }\end{array}$ & $\begin{array}{c}\text { Number of } \\
\text { occurrences } \\
\text { (written) }\end{array}$ & Total \\
\hline Imperatives & 35 & 86 & 121 \\
\hline Interrogatives & 28 & 20 & 48 \\
\hline $\begin{array}{c}\text { Fragments (e.g. yes, } \\
\text { no, NP) }\end{array}$ & 16 & - & 16 \\
\hline Declaratives & 4 & 3 & 7 \\
\hline
\end{tabular}

${ }^{10}$ A distinction is drawn between written and spoken texts because differences between these modes of language use will be shown to modulate both position of please and its (apparent) compatibility with a range of clause types, including in cases of speech representation in writing. 


\begin{tabular}{cccc}
\hline Standalone & 2 & 4 & 6 \\
\hline Conditional & 1 & - & 1 \\
\hline Total & 86 & 113 & 199
\end{tabular}

With respect to different clause types, imperatives are the most common clause type to contain please in both spoken and written texts, followed by interrogatives. Given that these are the canonical forms for requesting, that may not seem surprising. In contrast, please is rare with declaratives in either speech or writing. The fact that please occurs in declaratives at all, given that they are not used to express direct requests, deserves scrutiny.

\subsubsection{Declarative clauses and standalone 'please'}

Please appears in the following declaratives in the ICE-GB corpus; (14) shows please in declaratives in spoken contexts and (15) in written contexts, though note that all examples of please in (15) are contained within representations of speech.

(14)a. I'll have white ice cream please.

b. I'll have strawberry ice cream please.

c. So I ask for single questions please.

d. I want to hear what the witness says please.

(15)a. "Please, he's my son."

b. "Please, Brett...I hate to see you angry like this."

c. The policeman said, "I'd like your full name and address, please." 
The examples in (14) and (15c) all contain utterance-final please, which I will address in section 3.3. (15a, b) are more unusual as the only examples of utterance-initial please in declaratives in this corpus and both are written representations of speech. Please in these sentences appears not to be integrated into the syntax of the declarative clause as indicated by the comma punctuation. Moreover, please in these contexts is not directly linked to the statement made but seems to be elliptical if we follow the logic for antecedentless ellipsis worked out by Weir (2014). For (15a), for example, we could imagine underlying structures as in (16).

(16) a. Please [can you drop your threat to this man], he's my son. b. Please [spare him], he's my son.

In $(16 a, b)$, I claim that the material between square brackets is elided in line with wellestablished ellipsis accounts for fragments such as Merchant $(2001,2004)$-please is focused (either in situ in its initial position or it is fronted to the left edge of the sentence), followed by ellipsis of the non-focused material. In the semantics, all focused material in the clause is replaced by existentially-closed variables (in this case, the rest of the clause, referred to as the focus-closed clause). According to Merchant, this ellipsis is syntactically licensed by the $[E]$ feature on the head of the phrase in which the focused element (here please) is to be found ${ }^{11}$ and semantically licensed by the

\footnotetext{
${ }^{11}$ Merchant characterises this head as a functional head in the left periphery. Evidence exists that speech act heads, as functional heads in the left periphery, can carry the [E] feature (see work on metacommunicative-why-fragments by Woods \& Vicente 2017).
} 
existence of some antecedent clause which, when focus-closed, matches the focusclosed elided clause.

Typical morphosyntactic tests for the presence of ellipsis, such as case connectivity, are not appropriate as the form of please does not vary based on the content of the ellipsis site. However, possible responses to (15a) seem to suggest that the content in square brackets in (16) is present. (15a) without please, presented as (17A), is a declarative and, as such, has evaluable truth conditions: it can be accepted or challenged, as in $\left(17 \mathrm{~B}, \mathrm{~B}^{\prime}\right)$.

(17) A. He’s my son.

B. No, he's not/Yes, he is.

B'. That's true/That's not true.

B". \#I can only do what I've been ordered.

Any response to (17A) that is not an evaluation of the truth conditions should be in some way thematically linked to (17A) to ensure a coherent discourse- - how one might formalise such 'thematic linking' depends on the chosen model of discourse. (17B") does not appear to link in any clear way to (17A) — note that I purposely give no additional context to help the reader in forming such a link. Compare now (15a) containing please, repeated as (18A).

(18) A. Please, he's my son.

B. No, he's not/Yes, he is.

$\mathrm{B}^{\prime}$. That's true, he is./That's not true, he's not. 
B". \#That's true, I can/That's not true, I can't.

$B^{\prime \prime \prime}$. (No,) I can only do what I've been ordered.

$\left(18 \mathrm{~B}, \mathrm{~B}^{\prime}\right)$ remain contextually appropriate responses because of the presence of [he's my son] in (18A) - they can target the truth of [he's my son] for evaluation but not any other contextually available meaning, cf. the infelicity of $\left(18 \mathrm{~B}^{\prime \prime}\right) .\left(18 \mathrm{~B}^{\prime \prime \prime}\right)$, however, is now felicitous despite a lack of additional context. Please clearly communicates some kind of request and that request must be covertly structured as an imperative or a

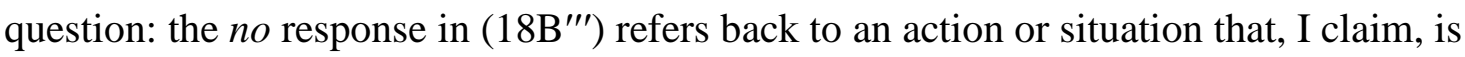
contained in the ellipsis site. Importantly here, it is both the use of the ellipsis and any contextual inferences introduced by please that lead to successful interpretation by the addressee, as Weir also notes (2014: 133).

Weir (2014) accounts for antecedentless ellipsis, that is, fragment utterances, by claiming that the antecedent for the ellipsis (and for anaphora in the subsequent responses) is not a syntactic object per se but the union of answers to the Question Under Discussion (QUD, Weir 2014: 130). In the case of fragment please, which is above the propositional content of the clause, the antecedent seems simply to be the QUD itself. As an example, the QUD in (16a/17a/19) is something like Can you drop your threat to this man? Formally this plays out as follows; $\llbracket \mathrm{E} \rrbracket^{\mathrm{F}}$ refers to the focusclosed elided clause:

(19) [F Please] ean you drop your threat to this man - he's my son.

a. QUD (implicit) $=$ Can you drop your threat to this man?

b. $\llbracket \mathrm{E} \rrbracket^{\mathrm{F}}=$ Can you drop your threat to this man? 
c. $\mathrm{QUD}=\llbracket \mathrm{E} \rrbracket^{\mathrm{F}}$, therefore ellipsis is licensed.

Crucially, if this ellipsis account for standalone please is correct, then we predict that we will not see examples of initial please without a prosodic break in indirect requests. This is because indirect requests are simply declaratives like any other and based on the evidence so far, the only initial please available with declaratives is the kind with an elided antecedent that we have seen in this section. This jibes with the lack of data in the corpus and the unacceptability of constructed cases like (20).

Context: You are asked what you would like for your 18th birthday.

*Please I've always wanted a car. （with no intonational break)

This supports the analysis of initial please as truly contingent on structurally specified illocutionary force, and not pragmatically determined interpretations of individual sentences in context.

Returning to the corpus data, then, I claim that we do not see any true examples of syntactically integrated please in initial position in declarative clauses as they are all utterance-initial standalone pleases, which are not syntactically integrated.

\section{2 (Other) characteristics of 'please'}

In addition to its clausal position and the type of clause it may occur in, the distribution of please is restricted in other ways.

\subsubsection{Embedded contexts}


Initial and medial please are restricted in embedded clauses. Excluding representations of direct speech, we find only one medial example as shown in (21a), though we find other examples in the British National Corpus $\left(\mathrm{BNC}^{12} ; 21 \mathrm{~b}-\mathrm{c}\right)$ :

(21) a. I wonder if we could uh uh someone would please propose for treasurer.

ICE-GB

b. I asked if they would please call me Richard — Dick, I said, made me feel like a symbol of some kind.

BNC, CL2 2285

c. So I left her $£ 10$ and asked her to please tell the warden if she saw her again so that he could call me with any news BNC, HWM1402

Interestingly, however, please is not available in initial position in cases like these with an overt complementiser, as shown in $\left(21 \mathrm{a}^{\prime}\right)$.

$\left(21 a^{\prime}\right)$ I wonder (*please) if (*please) someone would propose for treasurer.

In the absence of a complementiser, however, initial please may be licit:

(22) a. He asked me would I go to the dance with him.

b. He asked me please would I go to the dance with him.

c. He asked me would I please go to the dance with him.

\footnotetext{
${ }^{12}$ Data cited herein have been extracted from the British National Corpus, distributed by the University of Oxford on behalf of the BNC Consortium. All rights in the texts cited are reserved.
} 
d. *He asked me whether please would I go to the dance with him.

e. ${ }^{*}$ He asked me whether would I please go to the dance with him.

North West England dialect

The examples in (22) are of a dialect phenomenon known as Embedded Inverted Questions (EIQ; see McCloskey 2006, Woods 2016a, b for more detail). To foreshadow the analysis in section 3, EIQs are analysed as embedded root phenomena and, as please will be analysed as a functional head in the speech act structure, EIQs are expected to permit initial please.

Turning to final please, when it occurs with a prosodic break tends to associate with the main, not embedded clause:

(23) a. Can you find out when the kids need picking up, please?

$\rightarrow$ Interpretation: 'Can you find out please...'

b. *I found out when the kids need picking up, please.

However, in cases of EIQs (24a) and free indirect discourse (24b), final please seems to be able to associate with the embedded clause:

(24) a. He asked could he see my license please.

b. She asked if she might see a hand-mirror, please $[\ldots]$ ICE-GB

I will return to this issue in section 3.3. 


\subsubsection{Modification and coordination}

Unlike most adverbs, but like functional heads, please cannot be modified, as (25) shows (see also Stubbs 1983).
(25) a. *Very please. (cf. very kindly)
b. *Hugely please. (cf. hugely grateful)
c. *Many please. (cf. many thanks)
d. *Most please. (cf. most grateful)

Note that the idiomatic phrase pretty please is not considered to constitute a case of modification of please in any productive sense.

Adverbs can also typically be stacked or co-ordinated, where functional heads in the same projection cannot. This is illustrated using German discourse particles in (26) and in English in (27).

(26)*gehen Sie doch und mal zum Arzt.
go you PRT and PRT to.the doctor

'Go to the doctors!'

Coniglio (2005: 30)

(27)*Please and fine, fetch me the bucket.

Final please appears to be able to stack with other discourse markers like thank you, though it seems odd if coordinated with the same markers.

(28) a. Fetch me the bucket, please, thank you.

b. ??Fetch me the bucket, please and thanks. 


\subsubsection{Are all interrogatives equal?}

As mentioned in section 1, not all interrogative clauses can contain initial please. This is shown below in (29), in which information-seeking questions that cannot be construed as requests are incompatible with initial please.

(29) a. Please will you find me a partner?

b. Please can you persuade him to come?

c. *Please did you get that dress at Macy's?

d. *Please where did you get that dress?

Sadock (1974)

Sadock (1974) claims that there is no difference in meaning between examples like (29a), a polar interrogative with a modal auxiliary, and (29c), a polar interrogative with do-support, that should make them more or less appropriate with regards to please. He illustrates what he means by 'a difference in meaning' using examples such as (30).
(30) a. Feed the cat.
b. Feed the dog.

In the case that you only have a cat, telling me to feed the dog is inappropriate due to the meaning of the constituent parts of the sentence. Sadock argues that this is not the case with (29a) and (29c) because a context could be constructed in which (29c) too is grammatical. However, this is not strictly the case - the structure of the sentence must change to make (29c) grammatical, as (31) illustrates. 
(31) Context: A really wants to know where B got the dress because owning the dress will make A's life immeasurably happier, but B is refusing to tell A where the dress came from. A resorts to guessing.

A: Please - did you get the dress in Macy's?

In (31), please is an example of standalone please (also Sadock 1974: 89); therefore, it appears to combine with the information-seeking question in (31c), yet is already associated with a canonical requesting clause that has been elided (see section 2.1.2). Some possible underlying structures for (31c) are shown in (32).

(32) a. Please [tell me] - did you get the dress in Macy's?

b. Please [stop teasing me] - did you get the dress in Macy's?

c. Please [will you tell me the answer] - did you get the dress in Macy's?

The data above suggest that syntactically integrated initial please is only compatible with imperatives and polar questions with modal meaning. Given that the interrogatives in $(29 a, b)$, but not other kinds such as those in $(29 c, d)$, permit syntactically integrated initial please, a simplistic one-to-one correspondence between clause type and illocutionary force cannot be upheld.

\section{IS PLEASE AN ILLOCUTIONARY ACT HEAD?}

In this section I investigate precisely where each of the three pleases is generated in phrase structure and how the clause type restrictions fall out from this and from other contributing factors. 


\subsection{Initial 'please'}

\subsubsection{Initial 'please' is a head marking requesting illocutionary force}

Initial please clearly merges high in the clause, not only because of its tendency to be the first item linearly but also because we have already seen that it is incompatible with overt complementisers as in $\left(21 \mathrm{a}^{\prime}\right)$ and (22). Assuming a Cinque (1999)-style hierarchy of adverbial positions in the $\mathrm{CP}$ layer, it is not the absolute highest element in the clause as it seems to obligatorily follow speech act adverbs (33). ${ }^{13}$ However, it can follow or precede evidential $^{14}$ adverbs (34) and clause-peripheral vocatives (35) and always precedes elements in C, such as auxiliaries (36).

(33) a. Seriously, please can you help?

b. *Please, seriously can you help?

c. Seriously, please do stay a while.

d. *Please, seriously do stay a while.

(34) a. Obviously, please do stay a while.

b. Please, obviously do stay a while.

${ }^{13}$ I do not test evaluative and epistemic adverbs here, both of which are also high in Cinque's hierarchy, because both are independently awkward with questions and imperatives. This is possibly relevant but will be left for future consideration.

${ }^{14}$ Interestingly, obviously was the only evidential adverb that I could get any positive grammaticality judgements for - allegedly, clearly and apparently were all judged ungrammatical in all configurations. I speculate that this might relate to obviously's increased ease of being interpreted with respect to the addressee but leave this speculation for future work. 
(35) a. Saleh, please can you help?

b. Please, Saleh, can you help?

c. Saleh, please do stay a while.

d. Please, Saleh, do stay a while.

(36) *Can, please, you help?

Initial please also meets other criteria for high functional heads as proposed by Cardinaletti (2011) and Haegeman (2014). Please is derived from a verbal root (though it itself does not inflect). We have already seen that it may not be modified or coordinated with other similar elements. It is not truth-conditional but does contribute to the interpretation of the sentence. Its contribution is to communicate the intentions and commitments of the speaker in making that utterance and it restricts the clause containing it to a request interpretation, even if another or several other types of force are usually compatible with the structure and truth-conditional content of that clause.

Following an amended version of the speech act phrase structure proposed by Hill (2007b) ${ }^{15}$, the proposed structure for a sentence like (37a) is shown in (37b).

${ }^{15}$ For explicit illustration of how different approaches to Cartography and speech act structure compare and contrast, see section 4. 
(37) a. Seriously, please will you close the door?

b.

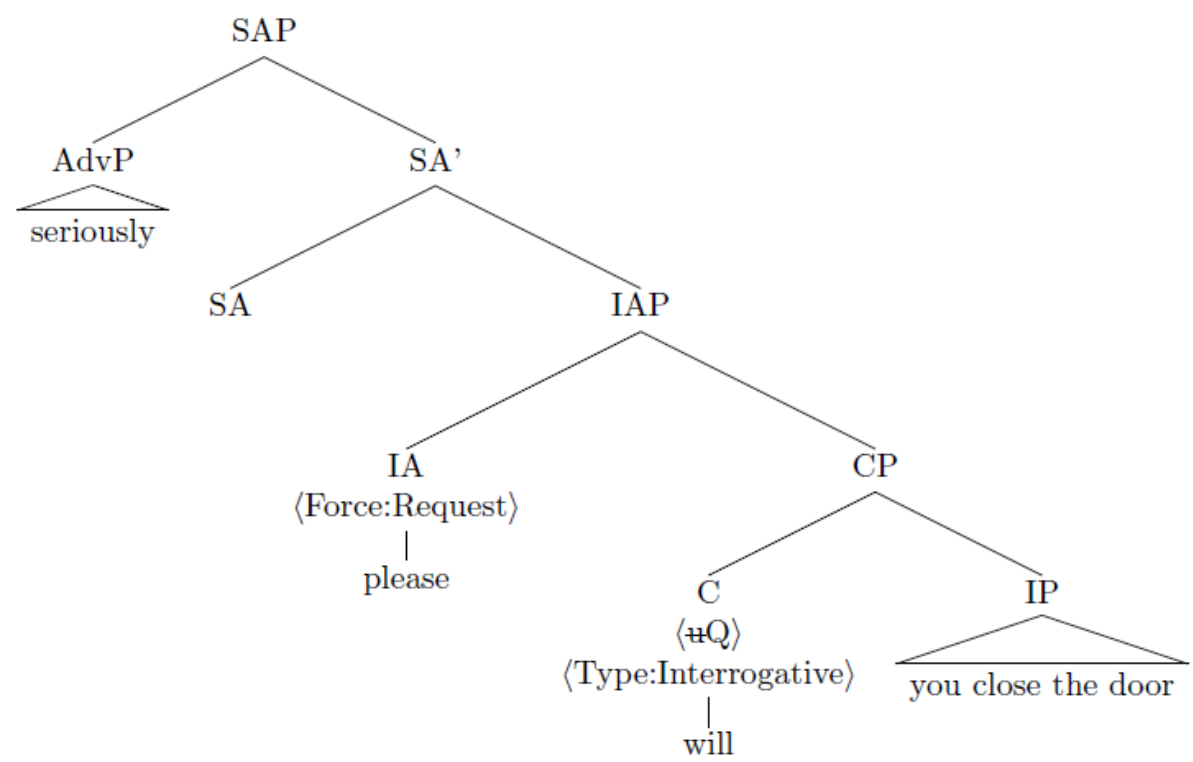

First some notes on notation. The IAP, headed by please, is the Illocutionary Act Phrase (cf. Krifka 2014 for an early use of this term in this context), where elements that are closely linked to but separate from clause type are merged. These elements convey information about the speaker's intentions in uttering the content contained within $\mathrm{CP}$ in the form in which it is uttered. I therefore propose that the IAP is also the phrase to which evidential adverbs, for instance, adjoin, as in (38), and vocatives ${ }^{16}$, as these express overtly the speaker's intention as to the identity of her audience (39): [IAP [AdvP Obviously] [IA' [IA please] [CP do stay a while] ] ]

(39) [IAP [DP Saleh] [IA' [IA please] [CP do stay a while] ] ]

\footnotetext{
${ }^{16}$ I do not have anything to say about the structure of vocatives in this paper so label them simply DP; see Hill $(2007 b, 2014)$ for more on their structure in a similar speech act framework.
} 
The SAP, in contrast, is the Speech Act Phrase, where elements that are not dependent on clause type but which convey information about speaker expectations for the addressee's interpretation of the utterance. This captures the spirit of Hill's (2007b) use of split SAPs to understand the ordering of adverbs, vocatives and discourse particles in the Romanian left-periphery while looking to distinguish between the roles of each SAP projection.

The syntactic proposal above also allows us to model why please and evidential adverbs/vocatives can vary in their ordering. If we assume that please can move to the SA head, we predict please>evidential adverb/vocative orderings without interfering with the strict speech act adverb>please order. This proposal echoes observations by Hill (2007b) on Romanian discourse particle hai, often translated as please, which shows the same ordering with respect to speech act markers and vocatives, as well as Haegeman's (2014) analysis of West Flemish discourse particles that may move from the lower to the higher SA head. This order seems to stress that the speaker really wishes the addressee to fulfil the request, so may be motivated by an uninterpretable information-structural feature on the SA head that is satisfied by movement of the IA head, as schematised in (40).

(40) $\left[\mathrm{SAP}\left[\mathrm{SA}[\mathrm{IA} \text { please }]_{\mathrm{i}}\right]\right.$ [IAP [AdvP obviously ][IA' [IA $\left.\mathrm{t}_{\mathrm{i}}\right]$ [CP do stay a while] ] ] ]

\subsubsection{Illocutionary force cross-cuts clause types: where syntax meets semantics}

In terms of the relationship between please in the IA head and the clause typing head, C, we could adopt a feature-checking relation, sensu Coniglio \& Zegrean 2012. The relevant part of their analysis idea is outlined, using their formatting, in (41). 
(41) ILL FORCE [utype] [val]/[iintent] [val] $\rightarrow$ intentionality valued CLAUSE TYPE [itype] [val] $\rightarrow$ clause type valued

Coniglio \& Zegrean (2012: 249)

However, please cross-cuts clause types, particularly within interrogatives, and while we could (at a push) attribute this to an incompatibility with [wh]-features to explain the distinction between polar and wh-questions, it is hard to see how a feature checking analysis would distinguish between polar and alternative questions. What we need instead is a way to distinguish between polar questions (and imperatives) as pleasecompatible types on the one hand and wh-/alternative questions (and declaratives) as non-please-compatible types on the other. This requires finding a relevant property or properties that link(s) polar questions and imperatives and that do(es) not apply to either declaratives or wh-questions.

Informally, the difference can be described as follows. Polar questions and imperatives share two characteristics: there exists a single proposition or property at issue and, as yet, that proposition or property is not truth-conditionally evaluable in the current world (see van Rooy \& Šafářová 2003, Krifka 2018). In the case of declaratives and wh-/alternative questions only one of these two characteristics holds: a single proposition is at issue in declaratives but it is truth-conditionally evaluable; whereas wh-/alternative questions are not truth-conditionally evaluable but multiple propositions 
are at issue. This reduces down to a single empirical description: yes $/ O K^{17}$ and $n o$ are appropriate answers to both polar questions and imperatives but not to either declaratives or wh-/alternative questions. But how do we formalise this?

Starting with polar questions, we might call upon a categorial approach (Ajdukiewicz 1938, von Stechow \& Zimmerman 1984 i.a.) to formalise their meaning as this approach specifically looks to distinguish yes/no questions from wh-/alternative questions. Krifka's (2001: 288) version of this approach characterises questions as functions that yield a proposition when applied to the meaning of their short answer. In the case of polar questions, their short answer is yes/OK or no which are considered functions from propositions to propositions. Polar questions therefore denote a set of functions from propositions to propositions and are of semantic type $<<<s, t>, t>, t>$ (Šimík 2011: 24-5). Wh-/alternative questions denote different things and hence are of different types depending on their answer. Declaratives denote propositions, which are functions from possible worlds to truth values and are of type $\langle\mathrm{s}, \mathrm{t}\rangle$.

What about imperatives? Portner (2004: 237) analyses imperatives as properties, as simple imperatives like (42) "denote something like the property of leaving".

\section{(42) Leave!}

Properties are of type $\langle\mathrm{e}, \mathrm{t}\rangle$, as they require the input of an entity to whom the property applies to return a truth value. One-place predicates such as [walk] are therefore also

\footnotetext{
${ }^{17}$ I add $O K$ to the mix here as it explicitly expresses assent, whereas yes may also just express agreement - a related notion but not the relevant notion in the case of imperatives.
} 
analysed as <e,t>, as are subject wh-questions like 'Who walked?' in categorial approaches to question meaning (Šimík 2011: 25). Yet of these, only imperatives can be answered with yes/OK or no. Portner also notes that the entity to whom the property can apply to return a relevant truth value is the addressee $(2004: 240)^{18}$; this is clearly not true of one-place predicates or subject wh-questions, which can take a range of possible entities as their input. The type of imperatives must therefore be differentiated from these other instances of type $<e, t>$.

Consider now the purpose of uttering an imperative - to make the world as the speaker wishes it to be or, on a smaller scale, to make some proposition be true; in the case of (49), that the addressee has left be true. We can therefore argue that, when an addressee answers yes/OK or no in response to an imperative that these words are also functions from some input - the content of the imperative - to a proposition; or in other words, functions from a property to a proposition. By analogy with polar questions, therefore, imperatives denote their answers: they denote a set of functions from properties to propositions and are therefore of type $\langle\langle<e, t\rangle, t\rangle, t\rangle$. Another reason for thinking that the ultimate output of an imperative is a proposition is to be found in the long response to an imperative, which is not a property, but also a proposition.

If the above reasoning is correct, we can understand please's distribution on the basis of semantic composition. Assuming flexible types, please takes an argument $\mathrm{S}$ of a complex type $<<<\sigma, t>, t>, t>$. It then returns the unique utterance $u$ such that $u$ is

\footnotetext{
${ }^{18}$ Portner achieves this through a domain restriction on the argument to which the property applies (2004: 240). This is necessary in the approach taken above as well, the key difference between the two approaches being the accommodation of the fact that imperatives can be answered with yes/OK or no rather than circumscribing the worlds in which they are or are not defined.
} 
mapped onto $\mathrm{S}$, where the propositional content of $\mathrm{u}$ and $\mathrm{S}$ are identical, the difference being that $\mathrm{u}$ is marked as a request. ${ }^{19}$ This is a similar proposal to that made by Lahiri (2002) for Spanish question-utterances: he proposes that there is a type coercion rule that lifts expressions of type $\langle s, t>$, that is propositions, to utterances (a type of entity). I do not think that the role of please is to coerce a question into an utterance entity because this is simply the canonical, not some ancillary or secondary, use of initial please. However, I suggest that the same kind of logic applies, whereby the input to the function denoted by the IA head please can be either a polar question of type $<<<\mathrm{s}, \mathrm{t}>, \mathrm{t}>, \mathrm{t}>$ or an imperative of type $<<<\mathrm{e}, \mathrm{t}>, \mathrm{t},>\mathrm{t}\rangle$ and the output is an utterance marked with requesting force.

\subsubsection{Summary}

The analysis in this section uses a generative syntactic framework, along with evidence from compositional semantics, to conclude that initial please is the head of the Illocutionary Act Phrase, a high projection in the clausal spine above CP. It encodes requesting force and takes clauses of the complex type $<<<\sigma, \mathrm{t}>, \mathrm{t}>, \mathrm{t}>$ as input and returns an utterance. As a result, it is incompatible with declarative clauses, which are of type $\langle\mathrm{s}, \mathrm{t}\rangle$ and non-polar questions, whose types depend on their short or constituent answer. This also accounts for the unembeddability of initial please, except in those cases that permit the embedding of illocutionary acts, that is, embedded clauses that are specified for illocutionary force in addition to clause type such as EIQs and free indirect discourse.

${ }^{19}$ Thanks to Norman Yeo for making me clarify my thinking here. 


\subsection{Medial 'please'}

This subsection focuses on medial please, beginning with its similarities with initial please and moving onto the differences in its distribution. I argue that medial please is phrasal but associates with the initial IA head, from which it gains its interpretation and its scope. In this way it aligns with other clause-medial discourse particles in Germanic (Bayer \& Obenauer 2011, Thoma 2016).

\subsubsection{Similarities with initial 'please'}

Medial please, like initial please, restricts its clause to a request interpretation. This is illustrated for interrogatives (43), declaratives (44) and imperatives (45). (46) shows that it is not available in indirect requests.

(43)a. Can you open the window?

Request or information-seeking question

b. Can you please open the window?

Request only

(44)a. Visitors will leave shoes at the door.

Statement or indirect request

b. Visitors will please leave shoes at the door.

Request only

(45) a. Everybody ${ }^{20}$ stop what they're doing.

Request or command

b. Everybody please stop what they're doing.

Request only

(46) It's (*please) a bit warm in here...

Indirect request

${ }^{20}$ Everybody here is an overt subject rather than a vocative on prosodic grounds; see Rupp (2003) for more details. 


\subsubsection{More on declaratives}

We see from (44) above that medial please has a different distribution from initial please as it can additionally occur in declaratives. However, it is only available in declaratives with deontic modal force expressing necessity or ability: the examples in (47) are attested, if considered awkward by some native speakers of English.
a. \%Persons anxious to write their names will please do so on this stone only. ${ }^{21}$
b. \%Ladies must please remain fully dressed while bathing. ${ }^{22}$

However, if a modal expressing possibility such as may or might $t^{23}$ is switched in to (47) the example becomes degraded, even for speakers who unproblematically accept (47):

${ }^{21}$ Taken from www.reddit.com/r/funny/comments/2gr9ol/a very british response to graffiti/ - thanks to Jason Overfelt for sharing this.

22 Taken from http://www.tripadvisor.co.uk/LocationPhotoDirectLink-g297637-i214 53673-ThiruvananthapuramTrivandrum Kerala.html.

${ }^{23}$ Might might be felicitous with medial please if must be interpreted in its (increasingly archaicised) sense as a deontic necessity modal. Imke Driemel (p.c.) notes that when the German bitte ('please') is inserted into a sentence with a deontic possibility modal, that modal must then be interpreted as a deontic necessity modal. This same interpretive shift is illustrated by the differences in felicity shown in (i).

(i) a. I wonder if someone might check the books, though they don't have to. b. I wonder if someone might please check the books, \#though they don't have to. 
(48) a. ??Persons anxious to write their names may/might please do so on this stone only.

b. ??Ladies may/might please remain fully dressed while bathing.

\subsubsection{More on polar questions}

Differences between initial and medial please also obtain when considering their interaction with negation in polar questions. (49) is a reference example without negation, (50) contains $n$ 't negation and (51) not negation.

(49) a. Please can you take a shower when you get home?

b. Can you please take a shower when you get home?

(50) a. ??Please can't you take a shower when you get home?

b. Can't you please take a shower when you get home?

(51) a. Please can you not take a shower when you get home?

b. Can you please not take a shower when you get home? ${ }^{24}$

c. *Can you not please take a shower when you get home?

In $(50 \mathrm{a}, \mathrm{b})$, the interaction between the high negation and please results in two very different outcomes. The 'base' question 'Can't you take a shower when you get home?' is ambiguous between three readings: firstly, checking the positive proposition 'you can have a shower'; second, checking the negative proposition 'you cannot have a shower';

${ }^{24}$ This also holds in declaratives, as in this naturalistic example (Schaar 1981: 169):

(i) Tell him that you're sorry, but he will have to wait in line like everyone else, and he should please not ask for special treatment. 
third, suggesting that 'you can have a shower' (Ladd 1981, Romero \& Han 2004, i.a.). The first two readings occur when speaker belief appears to be in conflict with the discourse situation and the third when speaker belief is not at conflict with the discourse situation (cf. Romero \& Han 2004: 618).

At first blush it may seem that the degraded status of (50a) is due to two different illocutionary acts being simultaneously marked — checking (through use of high negation) and requesting (through use of please). Checking, according to Jamieson (2017), is a specific speech act in which the speaker asks the addressee to confirm that the relevant proposition already exists in the discourse as shared by the two interlocutors. But if this is the case, why is (50b) acceptable despite containing high negation? The scopal relationship of please and negation seems to be crucial—please scopes over the property [have a shower] such that the speaker requests that that property become true of the subject [you]. The negation on the other hand seems to scope over something higher than the proposition altogether (cf. Holmberg 2016: 188) and the reading in which a proposition is checked does not obtain-only the suggestion interpretation is present. ${ }^{25}$ This reading appears to further mark the interrogative as a desire on the part of the speaker that the world be a certain way, bolstering the meaning

\footnotetext{
${ }^{25}$ Suggestions and check readings are distinct in non-modal high-negation questions, such as 'Isn't Jane coming?' but may be conflated in modalised high-negation questions with second-person subjects - that is, questions that constitute canonical requests. I refer the reader to Romero \& Han (2004: 642-3) for more on the similarities between requests and suggestions and Romero \& Han (2004: 657-8) for the parallel case of polar information-seeking questions with high negation in which a suggestion reading obtains. I do not have the space in this paper to examine in detail how they may relate to one another and leave this for further work; nonetheless it seems plausible that some connection is present and relevant to understanding the data in hand
} 
contributed by please, as well as the speaker's belief that the addressee may not want to comply. In (50a), however, the question under please remains three-way ambiguous and while it could plausibly get the same interpretation as (50b), the competition between this interpretation and the checking interpretations that are incompatible with a request speech act degrade. In the presence of a context where the checking act is ruled out, (50a) improves, as in (52).

(52) Context: $S$ knows that A will be very dirty from a long fell run when A gets home. The shower has just been replaced and there's no reason to believe it's not working perfectly.

S: Please can't you take a shower when you get home, rather than sitting in your dirty running stuff?

Returning to (51a), whose base question is two ways ambiguous between a non-biased question and a question checking the positive proposition, it may be more readily construed as non-biased and as such constitutes a request to not take a shower. (51b, c) illustrate an important fact about the relative scope of negation and please; propositional negation must scope under please as in (51b); hence (51c) is ungrammatical.

This raises further questions about the nature of the negation in (50b), already alluded to above, in which negation c-commands medial please. Take also the famous example in (53):

(53) Won't you please, please help me? 
Crucially, (50b/52) and (53) express non-negative requests: in the first case the content of the request is to take a shower and in the second to help the speaker. It is outside the scope of this paper to determine the nature of the high negation in these cases, but it clearly does not function as local negation in the clause containing please.

\subsubsection{More on imperatives}

Despite their notoriously tricky-to-analyse syntax, the relative positioning of please in different types of imperative further provides interesting clues as to the syntax of medial please. In canonical imperatives with covert subjects like (54)-(55) it is not possible to know whether we're dealing with initial or medial please due to the lack of vP-external material. All that examples like (54) show us is that please must precede the verb.

(54) Please call for help!

(55) *Call please for help!

However, negative and emphatic imperatives require do-support, and some subjects may be overtly expressed. The paradigm for the position of please is as follows:

(56) Imperatives with overt subjects

a. Somebody please close the door when you leave.

b. ?Please somebody close the door when you leave. ${ }^{26}$

${ }^{26}$ This example is improved when please is somewhat stressed - this is also true of (69e). This is compatible with the idea that initial please may move from the IAP head 
(57) Imperatives with emphatic do-support

a. Do please close the door when you leave.

b. Please do close the door when you leave.

(58) Imperatives with overt subjects and emphatic do-support

a. Somebody do please close the door when you leave.

b. *Somebody please do close the door when you leave.

c. Please somebody do close the door when you leave

(59) Imperatives with $n$ 't negation

a. *Don't please close the door when you leave.

b. Please don't close the door when you leave.

(60) Imperatives with not negation

a. *Do not please close the door when you leave.

b. Do please not close the door when you leave.

c. Please do not close the door when you leave.

(61) Imperatives with overt subjects and negation

a. *Somebody/You don't please close the door when you leave.

b. *Don't anybody/you please close the door when you leave.

c. Please don't anybody/?you close the door when you leave.

d. ?Somebody/you do please not close the door when you leave.

e. ?Please somebody/you do not close the door when you leave.

to the SAP head as outlined in section 3.1.2, with the effect that the request is more strongly foregrounded. 
In sum, medial please must be positioned between the position of emphatic do and not negation, i.e. it is higher than vP but lower than the position of the tensed element in IP (see Laka 1990, Duffield 2013 i.a. for the postulation of a lower projection for emphatic $d o$ compared with dummy $d o)$. Moreover, regardless of whether $d o(+n ' t)$ in imperatives are both analysed as merged in IP (Rupp 2003), or as do in IP and don't in CP (Henry 1995, Potsdam 1996), it is clear that medial please must occur lower than these two positions and hence lower than IP, as don't is always incompatible with medial please. ${ }^{27}$ This could indicate that please is a positive polarity item (PPI) that may not be scoped over by negation. More support for this approach follows in section 3.2.5.

Further evidence that please is positioned above the vP edge comes from its ordering with respect to vP edge adverbs such as often and always in both imperatives and declaratives.

(62)a. *Do often please explore the fountain.

b. Do please often explore the fountain.

c. *You should often please explore the fountain.

d. You should please often explore the fountain.

e. Parents should (*always) please always refrain from congregating inside the front entrance or on the benches in front of the office area during arrival and dismissal times. $^{28}$

${ }^{27}$ That is, in imperatives - we have already seen that it is compatible with medial please in polar questions with high negation, though no truth-conditional negative meaning obtains in these cases. I will discuss this data further in section 3.2.5. ${ }^{28}$ Taken from http://www.framingham.k12.ma.us/mccarthy/documents/StudentHandbook2013.pdf. 
We can further pinpoint the position of please by investigating its distribution with respect to discourse adverbs. Cinque (1999: 84-6) claims that there is a fixed ordering of specialised functional heads and associated adverbs in the $\mathrm{CP}$ and upper IP layers. Most relevant to this paper is the claim that speech act adverbs (e.g. seriously, honestly) precede evidential adverbs (e.g. allegedly, clearly), which precede epistemic adverbs (e.g. probably, certainly). Belletti $(2001,2004)$ extends this branch of the Cartographic enterprise by noting that certain functional projections previously only considered part of the CP and uppermost IP can also be found lower in IP, just above the vP, such as topic and focus projections. Thoma (2016) also draws on these insights with respect to the relationship between adverbials and functional heads and follows Frey \& Pittner (1998) and Pittner (2000, 2004) in proposing that speech act and epistemic heads are available in IP, a proposal she demonstrates using discourse particles and their relationship with the relevant adverbs in the middlefield. She shows that discourse particles that scope at the level of the utterance fall into this space in IP by appearing below medial speech act adverbs but above medial epistemic adverbs. Given the analysis proposed for please, we expect the same outcome; if medial please is merged in a medial illocutionary act phrase, it should follow speech act adverbs (in SpecSAP) but precede evidential adverbs (which attach to IAP) and epistemic adverbs (which attach somewhere between IAP and vP). The data follows:

(63)a. You should seriously stop replying to those messages.

b. ?You should please seriously stop replying to those messages.

c. You should seriously please stop replying to those messages. 
(64)a. You should clearly stop replying to those messages.

b. *You should please clearly stop replying to those messages.

c. ??You should clearly please stop replying to those messages.

(65)a. You should probably stop replying to those messages.

b. You should please probably stop replying to those messages.

c. *You should probably please stop replying to those messages.

The position of please in the medial SAP/IAP layer mirrors its position in the initial SAP/IAP layer with one exception; it does not appear to be compatible with clausemedial evidential adverbs. If we follow Thoma (2016) and propose that medial please is a modifier rather than a head, then it appears to compete for the same position in SpecIAP as the evidential adverb. As such, neither order of please and evidential adverb is considered grammatical because in both cases the position of one of the items is undefined. Moreover, medial please, being phrasal cannot raise above the speech act adverbs in the same way as initial please can above vocatives. ${ }^{29}$

\subsubsection{The syntax of medial 'please'}

In the preceding sections I have determined that, like many other discourse particles, please behaves like a head when it is initial and a phrase when it is clause-medial. Thoma (2016: 53, also 300) summarises the mixed behaviour of discourse particles in German using table 3, which I have adapted for please.

\footnotetext{
${ }^{29}$ One question raised here is: what are the parallels that this description infers for vocatives and evidential adverbs? I will not address this but see Hill (2014) for evidence of a relevant relationship in Romanian address particles.
} 
Table 3

Phrasal properties of 'please'

\begin{tabular}{ccc} 
Property & Behaviour of please & Status of please \\
\hline Can be coordinated & No & $\mathrm{X}$ \\
\hline Can be modified & No & $\mathrm{X}$ \\
\hline $\begin{array}{c}\text { Can occupy C (or a higher } \\
\text { head) }\end{array}$ & $\begin{array}{c}\text { Yes (initial)/ } \\
\text { No (medial) }\end{array}$ & $\mathrm{X} / \mathrm{XP}$ \\
\hline Blocks head movement & $\mathrm{No}^{30}$ & $\mathrm{XP}$ \\
\hline $\begin{array}{c}\text { Complementary distribution } \\
\text { with evidential adverbs }\end{array}$ & $\begin{array}{c}\text { Yes (initial)/ } \\
\text { No (medial) }\end{array}$ & $\mathrm{X} / \mathrm{XP}$ \\
\end{tabular}

It is also clear that medial please must 'associate' with the head lexicalised by initial please in some way, in order to obtain its requesting meaning. Take (66), a paraphrase of (63c):

(66) Utterance: You should seriously please stop replying to those messages.

Paraphrase: [With seriousness [I request [you stop replying to those messages]]].

Response: \#That is (not) true.

I will (not).

The proposed syntax for medial please in an example such as (63c/66) shown in (67).

${ }^{30}$ Given that we do not yet have a good alternative analysis for high negation as in (53), we assume that negation starts out in an IP-internal NegP and must move across medial please in such cases. 
(67)

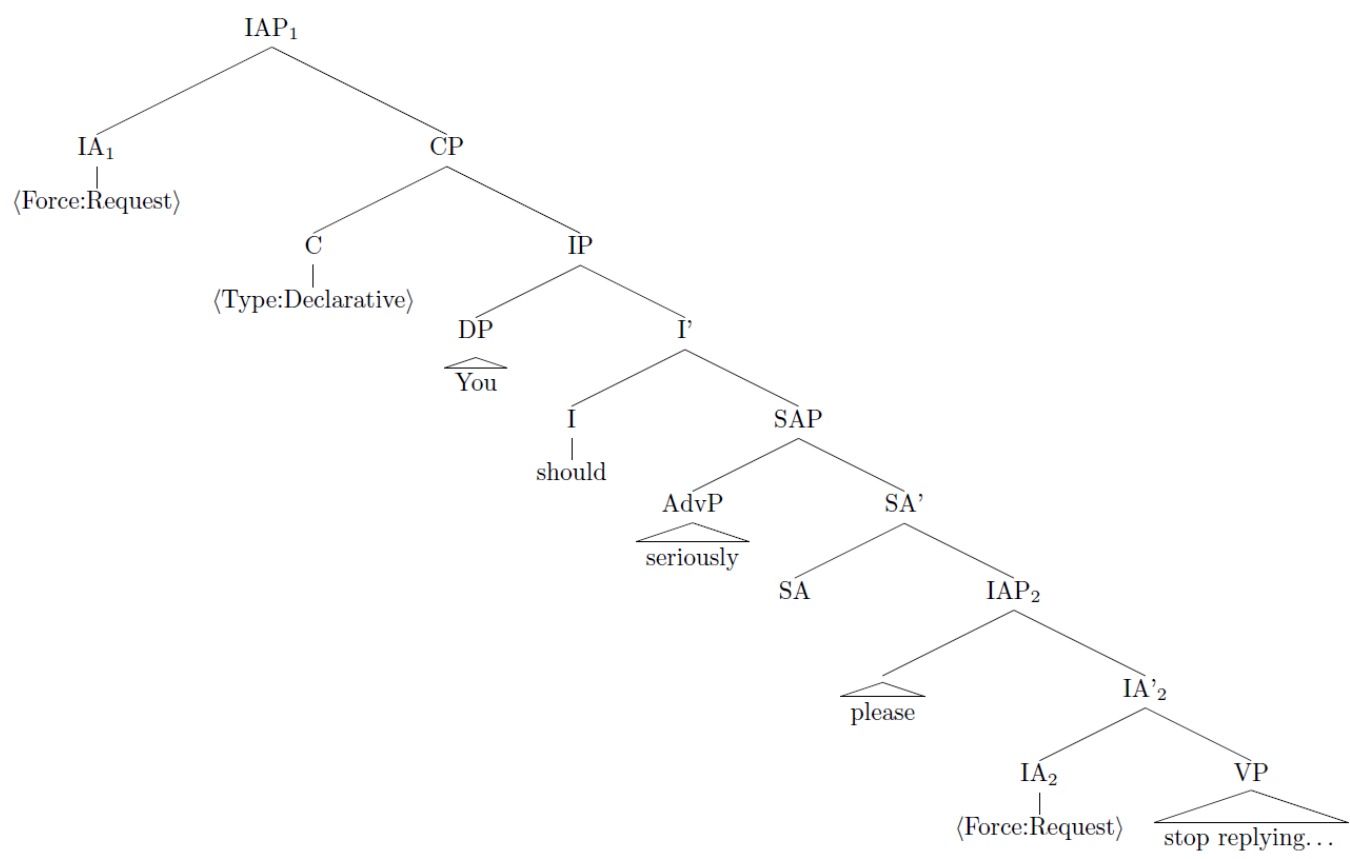

According to this proposal, medial please is a modifier merged in the specifier of a low illocutionary act phrase (IAP). Please is characterised here as a modifier rather than a head because, as outlined above, it does not block head movement from lower positions such as NegP. Moreover, as a clause-medial modifier, we do not expect medial please to impose the same clause type restrictions as overt initial please because it does not select a CP complement, and indeed this is what we find.

We must also consider the nature of the relationship between medial please and the initial IA head. Once again, we could take a feature-matching approach à la Coniglio \& Zegrean (2012), where medial please has uninterpretable features for both clause type and force which are checked by the $\mathrm{C}$ and IA heads. However, the postulation of such features brings with it assumptions about categorial status, which we might want to avoid given please's mixed categorial status (cf. Table 3). Thoma (2016) in her study of Bavarian discourse particles that have similar distributions, behaviours and mixed categorial status to please, appeals to Wiltschko’s (2014) Universal Spine Hypothesis to 
understand how medial particles obtain their interpretation. Wiltschko (2014: 163, 3245) claims that the function of a linguistic item such as a discourse particle depends on the functional category that that item associates with, such that the complete (i.e., not simply core) meaning of a given form is mediated through syntax rather than entirely lexically encoded. Formally, this association is mediated through a non-substantive grammatical feature [coincidence], proposed by Ritter \& Wiltschko (2014: 1336), that "makes a contribution to semantic interpretation without recourse to encyclopedic knowledge of any sort". In essentials, such an account still constitutes a featurechecking account, but avoids the problems of a Coniglio \& Zegrean-style approach because the [coincidence] feature imposes no categorial requirements on medial please. Instead, it simply formalises a link between a functional head on which the feature is interpretable and another linguistic item carrying an uninterpretable version. This mechanism ensures that requesting force only occurs in the presence of an IAP head endowed with requesting force ${ }^{31}$ and not with, for example, an assertive IAP head. The analysis above also explains why medial please, positioned between the tense position (here I) and the vP edge but dependent on a high IA head for its meaning, may only cooccur with deontic modals (or modals that can be coerced to have such a reading) when requesting force is present. Polysemous modals' meanings change depending on their scope relative to tense; deontic meanings occur when the modal scopes below tense and epistemic meanings when it scopes above tense (Cinque 1999:

\footnotetext{
${ }^{31}$ The correct analysis for embedded medial please in (21) may also fall out through this mechanism if we assume that the [coincidence] feature can be checked across clause boundaries (indeed, phase boundaries if we assume Chomsky 1995 et seq.). It would be then subject to the same local restrictions as any other medial please, which holds for data like (21).
} 
106, cf. also Hacquard 2010). As medial please must outscope all other markers of mood and modality, apart from speech act adverbs, yet we know it scopes below tense, it cannot occur with an epistemic modal as this will outscope it and, as an intervening functional head, prevent association of please with the head lexicalised by initial please (cf. Ritter \& Wiltschko 2014: 1363).

*He must please arrive at 9 (because it's now 8 and he's only a mile away).

The incompatibility of medial please and modals of possibility, in contrast, has a lexical basis: requests inherently require the addressee to commit to doing something and not simply to the possibility of something being the case.

\subsubsection{The semantics of medial please}

As for the composition of medial please, the fact that please only combines with complex types accounts for the way in which it can combine with substructures within TP; the type of a VP, namely <e,t> is a valid input for please. However, if medial please is exactly the same as initial please, a type-clash will occur, as initial please's output is an utterance entity where the required output to compose the VP plus please with the remaining structure will be type $\langle\mathrm{e}, \mathrm{t}\rangle$. This means the type of medial please is $\langle\langle\mathrm{e}, \mathrm{t}\rangle,\langle\mathrm{e}, \mathrm{t}\rangle\rangle$, the type of predicate-level modifiers, whereas the type of initial please is a type of head. This is commensurate with the claim that medial please has a slightly different function from initial please: it is not an utterance-level function that takes a clause and returns an utterance, but it is a predicate-level function that modifies only the predicate, taking the predicate as its input and returning another modified predicate. 
This approach also accounts for the unavailability of medial please with modal forces that cannot be interpreted as expressing necessity. Medial please marks the predicate as requested, so combining a predicate marked as requested with a modal that expresses a force other than obligation causes a crash in interpretation - in short, contradictory modal forces cannot combine.

\subsubsection{Summary}

In this section we have seen that medial please is not a head, but merges in the position of a medial illocutionary act modifier that associates via a [coincidence] feature with the initial illocutionary act head. It appears in polar interrogatives, imperatives, and declaratives with deontic necessity and ability modals, hence it is still compatible only with moods and modalities that can be construed as imposing a fulfillable obligation on the addressee. We have also seen that please must outscope (true propositional) negation and as such is a PPI restricted by locality.

On the account proposed here, medial please is a predicate-level version of the initial please outlined in the previous section. It modifies predicates to mark them as the core property of a request, meaning that it can occur in only those declaratives that have the same modal force as a request; namely, declaratives that impose an obligation on their addressee.

Why might this variant exist? A weak argument is that crosslinguistically, discourse particles and other discourse-related lexical items have clause-peripheral and medial variants, so at least this is not a surprising claim. Another avenue to pursue is that medial variants of discourse markers permit a speaker to circumvent syntactic restrictions on the language; it is potentially telling that V2 languages, which have 
limited free positions in the left-periphery (e.g. German), seem to make heavy (if not exclusive) use of clause-internal discourse particles (see Thoma 2016: 291-4) where Romance languages with more articulated left peripheries such as Italian and Romanian permit more clause-peripheral discourse particles (Cardinaletti 2001, Hill 2007a, Munaro \& Poletto 2004). Space does not permit a full crosslinguistic survey in this paper but I believe this is fertile ground for further research.

\subsection{Final 'please'}

As discussed in section 2, final please has a wider distribution than initial and medial please. It may occur with polar interrogatives and imperatives, but also with fragments such as yes or standalone NPs, and with certain declaratives, such as those uttered as responses to questions and overt performative requests. It is also possible with whquestions such as the 'classroom' examples in (69)-(70).

(69) Johnny, who discovered the Bronx, please? Sadock (1974: 121)

(70) a. Johnny, Jonas Bronck established which settlement, please?

b. Johnny, which settlement did Jonas Bronck establish, please?

However, final please patterns like initial please with respect to stacking with vocatives in either order:

(71) I'll have a coke please, Mary.

(72) I'll have a coke Mary, please. 
What then is the structure of final please? As a starting point, let us take Haegeman's (2014) approach to West Flemish utterance final particles and propose the following:

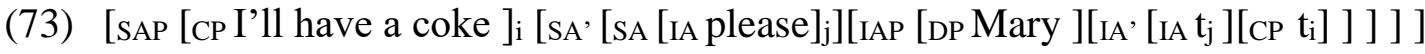

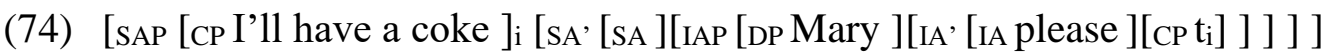

At this point, final please looks effectively like initial please, rendered final by the movement of the $\mathrm{CP}$ over the IA head, though this will be revised shortly. With respect to semantic composition, assuming that traces are of type e (e.g. Heim \& Kratzer 1998), we can analyse final please as combining only with type e. This approach would predict that all clause types would be forced to move above this please if they are to combine with it, or else a type-clash would result.

Three types of evidence suggest that this is not an ad hoc claim: (i) the combination of final please with elements of type e, (ii) the size of the clause that can move from under final please and (iii) differences in the interpretation and scope of final please compared with initial please. Take first the availability of proper names, which denote elements of type e, in combination with please, either finally or initially (75). While these could be dealt with through our QUD-ellipsis approach, an approach where the proper name combines directly with please better captures prosodic facts, especially when we compare such examples with other nominals of type $<\mathrm{e}, \mathrm{t}>$ or higher, which are ungrammatical (76).

(75) a. Mary please.

b. Please Mary. (Emphasis on please, no prosodic break) 

a. *Some boy please.
b. * Please some boy.
c. *A boy please.
d. *Please a boy.

Secondly, syntactic elements larger than $\mathrm{CP}$ can move past final please. It is possible in British English to produce an utterance with multiple instances of please in different positions, of which one will be in final position. A search in the $\mathrm{BNC}$ for multiple pleases separated by up to 6 other words returns examples like the following: ${ }^{32}$

$$
\text { Could anyone please post a full match report please? }
$$

BNC, J1H 1151

(78) Please can I have some stottie please?

BNC, KB8 2789

This suggests that final please can combine with the trace of an IAP. A revised analysis for final please is as follows:

(79) $\left[\mathrm{SAP}\left[\mathrm{IAP}\left[\mathrm{IA}^{\prime} \text { [IA Please }\right][\mathrm{CP} \text { can I have a coke }]\right]\right]_{\mathrm{i}}\left[\mathrm{sA},[\mathrm{SA}\right.$ please $\left.]\left[\mathrm{IAP}_{\mathrm{i}} \mathrm{t}_{\mathrm{i}}\right]\right]$

But what about vocatives and the mixed please $<>$ vocative ordering in (75)? To deal with final particles in Romanian and West Flemish, Hill (2014) suggests that the IAP layer (her SAH [Speech act hearer] layer) may be split in two, giving us the following:

\footnotetext{
${ }^{32}$ Interestingly we don't find examples in which initial and medial please are both realised, e.g. ??Please can you please help me?, which fits with the analysis of medial please as an alternative, complementary realisation of initial please.
} 
(80) $\left.[\text { SAP [IAP Please can I have a coke }]_{i}\left[\mathrm{SA}^{\prime} \text { [SA [ia please }\right]_{j}\right][$ iaP [DP Mary $]\left[\right.$ ia $^{\prime}$ [ia $\left.\mathrm{t}_{\mathrm{j}}\right][$ IAP $\left.\left.\left.\left.\left.\mathrm{t}_{\mathrm{i}}\right]\right]\right]\right]\right]$

(81) [sAP [IAP Please can I have a coke $]_{\mathrm{i}}\left[\mathrm{SA}^{\prime}[\mathrm{sA}]\left[\right.\right.$ iaP [DP Mary ][ia' [ia please ][IAP $\left.\left.\left.\left.\mathrm{t}_{\mathrm{i}}\right]\right]\right]\right]$

This structure predicts that full SAPs containing speech act adverbs, cannot be fronted above (and hence co-occur with) final please and that speech act adverbs will be in complementary distribution with final please. This is supported by the absence in corpora of constructions such as seriously/honestly/frankly ... please. It predicts that final please will only associate with the matrix clause and not the embedded clause, as IAP/iaP/SAP are not available in typical embedded clauses; this is confirmed by the data (see (23)). That said, in the case that the embedded clause is an iaP, as in EIQs or free indirect discourse (which can host a range of 'root' phenomena) ${ }^{33}$, we would expect to find final please associating with the embedded clause alone, as the embedded $\mathrm{CP}$ can raise to the embedded Spec,iaP. As shown in (24), this is indeed possible.

Our analysis also predicts a slightly different interpretation for final please as it instantiates a different head, the ia head, compared with IA head initial please. ${ }^{34}$ This is also what we find, both in our data and in the existing literature. In her contextual analysis of final please in American and New Zealand English corpora, Sato notes that "[t]he tokens of please at this particular [final] position function as a register marker which has more relevance to the situation than to politeness" (Sato 2008: 1267) and that

\footnotetext{
${ }^{33}$ See Eckardt (2014) for a recent formal semantic approach to free indirect discourse in which root phenomena are considered.

${ }^{34}$ The idea that West Flemish final particles are different items from the initial variants is mooted by Haegeman (2014) but not pursued.
} 
the requester-requestee relationship is well-established by the context in cases of final please (Sato 2008: 1268). Haegeman \& Hill (2013) and Haegeman (2014) talk about West Flemish final particles as expressing a "bonding" relationship between speaker and addressee, as opposed to the "attention seeking" relationship expressed by initial particles, ${ }^{35}$ and that is captured in our data too. Where initial please draws attention to the requesting force of the utterance, this cannot be maintained for final please given the availability of data like (14d), repeated here as (82):

(82) I want to hear what the witness says please.

ICE-GB

The declarative IP here does not canonically express a request, even if the predicate want indicates a desire for the embedded infinitive [to hear what the witness says] which, as a $\mathrm{CP}$ (or smaller), cannot be alone the target for please. The example does fit Sato's claims on final please, however, as the speaker (a lawyer) has the relevant relationship with the addressee (the judge) such that they can express a desire to hear the witness's testimony and be highly likely to have the fulfilment of that desire facilitated by the addressee. Final please here appears to reaffirm and reinforce this relationship, where initial please might be preferred in the case that the speaker does not 'automatically' have the right to request anything particular of their addressee. Experimental work on the finer details of this interpretive difference will constitute a fruitful next step in this research.

\footnotetext{
${ }^{35}$ See also Schaden (2010: 184) for a similar idea with respect to initial and final vocatives; thanks to anonymous reviewer for this suggestion.
} 
Despite the above claims, final please remains incompatible with indirect requests (see (46)). I claim that this is because the request-reaffirming 'bonding' meaning of final please is at odds with the non-transparent meaning and pragmatic conditions required for an indirect request (cf. House 1989: 104, Wichmann 2004: 1540-1); where final please builds on explicit requests within specific interlocutor relationships, indirect requests imply that the speaker does not want to or feel able to make direct requests of their addressee. There is no doubt that pragmatic and social factors interact with the felicity of please, but these factors work on top of the syntactic and semantic factors addressed in this paper; for more on the pragmatics of please, I direct readers particularly to the works referenced in this paragraph.

One final difference between initial/medial and final please is that final please is compatible with matrix negation:

(83) a. Charlotte I've got to finish, get home and feed this monster, don't do that please. BNC, KBH 5257

b. Don't fiddle with that please. BNC, KP3 989

This is despite the oddness of the following examples:
a. I don't want a drink, *please.
b. No, *please.

Examples like (83)-(84) suggest that tension between final please and negation is not a syntactic or semantic restriction so much as a pragmatic one similar to the pragmatic 
restrictions on questions containing negation. While questions such as 'Who didn't come to the party?' are fine in contexts where the list of likely partygoers is salient or somehow prescribed, they are infelicitous out of the blue as the set of non-partygoers in the world will be much larger than the set of partygoers. Similarly, the set of states that the requester would like the world to match will be smaller than the set of states that she does not want the world to match, hence non-negative requests are felicitous in a wider range of contexts and, as in the case of indirect requests, the speaker and addressee may only 'bond' over a proposition or property that may be fulfilled-including stopping an activity - but not one that results in no further action.

\section{HOW DIFFERENT APPROACHES TO SPEECH ACT STRUCTURE COMPARE}

Before concluding, a short but important clarification must be made. I have appealed to Cinque's cartographic approach and Hill's speech act structure in this paper so far. It is therefore useful to recapitulate how these approaches feed into the analysis here and how they relate to each other. Table 4 draws the parallels between these approaches, their terminology and the hierarchies they propose, as I understand it. I have also included Wiltschko \& Heim (2016) as another recent influential proposal.

Table 4

A comparison of approaches to speech act structure

This paper ${ }^{36} \quad$ Hill (2007b et seq) ${ }^{37} \quad$ Cinque (1999) $\quad$ Wiltschko \& Heim (2016)

\footnotetext{
${ }^{36}$ First used in Woods (2016b); Krifka (to appear) also adopts this structure on the basis of details not discussed in this paper but uses different terminology once again; for reasons of space, I refer the reader to that work for full exposition.

${ }^{37}$ Includes Haegeman \& Hill (2013), also employed in Haegeman (2014).
} 


\begin{tabular}{cccc} 
SAP & SASP $^{38}$ & SAP & RespP \\
\hline iaP & saP/SAP $_{1 / \text { sahP }}$ & ??EvaluativeP & GroundA \\
\hline IAP & SAP/SAP $/$ SAHP & ?EvidentialP & GroundS \\
\hline $\mathrm{CP}$ & $\mathrm{CP} /$ ForceP & - & $\mathrm{CP}$ \\
\hline- & & EpistemicP & - \\
\hline $\mathrm{IP}$ & $\mathrm{IP}$ & $\mathrm{T}_{\text {past }} / \mathrm{T}_{\text {future }}$ & IP \\
\hline- & & Irrealis $\ldots$ Asp piCompletive & - \\
\hline $\mathrm{SAP}_{2}$ & & - & - \\
\hline $\mathrm{IAP}_{2}$ & & - & - \\
\hline vP etc $\ldots$ & vP etc $\ldots$ & voiceP etc $\ldots$ & VP etc $\ldots$
\end{tabular}

The query on EvidentialP in the Cinque column is due to the fact that some, but not all, of the features of IAP are covered in Cinque's EvidentialP, so I do not wish to assume complete equivalence. The double query on EvaluativeP relates to the lack of attention given to this projection in this paper, but to postulate equivalence between it and iaP is the logical next step to examine. A point of divergence between Hill's structure on the one hand and Wiltschko \& Heim's on the other is the locus of speaker and addressee indices; the speaker is 'closer' to the propositional content in Wiltschko \& Heim, where the speaker dominates the addressee in Hill. This paper (and previous work) does not dedicate any particular projection to either speaker or addressee; I refer the reader to Woods (2016b) for more details on how the IAP and SAP differ and where discourse participant indices are represented. The parallels are therefore tentative, but should help the reader situate and evaluate my claims against their forebears (which have, of course, strongly influenced them).

We can further assume that, given Belletti's $(2001,2004)$ extension of Cinque's hierarchy to the space above $\mathrm{vP}$, the cells filled in this paper by $\mathrm{SAP}_{2} \ldots \mathrm{EpistP}_{2}$ may be

${ }^{38} \mathrm{SASP}=$ Speech Act $($ Speaker) Phrase; sahP/SAHP $=$ Speech Act (Hearer) Phrase. 
filled in the middle column by SAP... EpistemicP, but I note that here instead of in the table to maintain felicity to Cinque's (1999) work.

\section{CONCLUSION}

The distributional and interpretive data in this paper suggest that syntactically integrated clause-initial please in English is a request-marking functional head. This head please has the following key characteristics: it is base-generated in the head of an Illocutionary Act Phrase (IAP), restricting the clause types with which it can combine to imperatives and polar interrogatives. Other factors such as modality also affect its distribution, but syntax is clearly a key factor affecting the realisation of please, given its relative orderings with high adverbs and vocatives as well as its complete incompatibility with declaratives and wh-interrogatives. Initial please overtly marks the requesting force of the utterance it scopes over and it is prosodically part of the clause it gives force to.

When covert, the IA head please may associate with a clause-medial realisation please that patterns in its distribution like a modifier positioned between IP and the vP edge in a second, medial, IAP. Medial please continues to mark requesting force in a wider range of clauses including declaratives containing deontic modals of necessity or ability. Clause-final please, in contrast, is base-generated in iaP (above IAP), has different selectional properties, and does not mark requests but reinforces interdependent relationships between speaker and addressee, similarly to Haegeman's (2014) 'bonding' claim for clause-final West Flemish particles.

The existence of these two please functional heads supports recent proposals in theories of speech act syntax for interlocutor-oriented projections above CP that interact with but are separate from clause-typing heads. The work in this paper also supports the 
proposal that illocutionary force, narrowly defined, is marked in syntax, may be realised overtly in English, and has a clear impact on the interpretation of the clause and its role in discourse. Finally, the paper explicitly compares and contrasts for the first time Cartographic approaches to the left periphery and influential recent proposals in speech act syntax, finding that they are not only compatible, but in many ways equivalent. 
Author's address:

School of English Literature, Language and Linguistics Newcastle University

Newcastle-upon-Tyne NE1 7RU

United Kingdom

Email: rebecca.woods@newcastle.ac.uk 


\section{REFERENCES}

Aijmer, Karin. 2015. "Will you fuck off please". The use of please by London teenagers. Pragmática Sociocultural/Sociocultural Pragmatics 3(2), 127-49.

Ajdukiewicz, Kazimierz. 1938. Logiczne podstawy nauczania [The logical foundations of teaching]. Warsaw: Nasza Księgarnia.

Bayer, Josef \& Hans-Georg Obenauer. 2011. Discourse particles, clause structure, and question types. The Linguistic Review 28(4), 449-91.

Belletti, Adriana. 2001. Inversion as Focalization. In Aafke Hulk \& Jean Yves Pollock (eds), Subject Inversion in Romance and the Theory of Universal Grammar, 6090. New York: Oxford University Press.

Belletti, Adriana. 2004. Aspects of the Low IP Area. In Luigi Rizzi (ed), The Structure of CP and IP: The Cartography of Syntactic Structures, vol. 2, 16-51. Oxford: Oxford University Press.

Biber, Douglas, Stig Johansson, Geoffrey Leech, Susan Conrad \& Edward Finegan. 1999. Longman Grammar of Spoken and Written English. London: Longman.

Blum-Kulka, Shoshana. 1985. Modifiers as indicating devices: the case of requests. Presented at the Conference of Cognitive Aspects of the Utterance, Tel Aviv, Israel.

Bolinger, Dwight. 1978. Yes-no questions are not alternative questions. In Henry Hiż (ed), Questions, 87-105. Dordrecht: Reidel.

Cardinaletti, Anna. 2011. German and Italian modal particles and clause structure. The Linguistic Review 28, 493-531.

Chomsky, Noam. 1995. The Minimalist Program. Cambridge, MA: MIT Press. 
Cinque, Guglielmo. 1999. Adverbs and Functional Heads. Oxford: Oxford University Press.

Coniglio, Marco. 2005. Deutsche Modalpartikeln: eine syntaktische Analyse. MA dissertation, Università Ca’'Foscari di Venezia.

Coniglio, Marco \& Iulia Zegrean. 2012. Splitting up force: Evidence from discourse particles. In Lobke Aelbrecht, Liliane Haegeman \& Rachel Nye (eds), Main Clause Phenomena: New Horizons, 229-56. Amsterdam: John Benjamins.

Duffield, Nigel. 2013. On polarity emphasis, assertion and mood in Vietnamese and English, Lingua 137, 248-70.

Eckardt, Regine. 2014. The Semantics of Free Indirect Discourse. How Texts Allow us to Mind-Read and Eavesdrop. Leiden: Brill.

Frey, Werner \& Karin Pittner. 1998. Zur Positionierung der Adverbiale im deutschen Mittelfeld. Linguistische Berichte 176, 489-534.

Hacquard, Valentine. 2010. On the event relativity of modal auxiliaries. Natural Language Semantics 18(1), 79-114.

Haegeman, Liliane. 2014. West Flemish verb-based discourse markers and the articulation of the Speech Act layer. Studia Linguistica 68(1), 116-39.

Haegeman, Liliane \& Virginia Hill. 2013. The syntacticization of discourse. In Raffaella Folli, Christina Sevdali \& Robert Truswell (eds), Syntax and its Limits, 370-90. Oxford: Oxford University Press.

Heim, Irene \& Angelika Kratzer. 1998. Semantics in Generative Grammar. Malden, MA: Blackwell.

Henry, Alison. 1995. Belfast English and Standard English: dialect variation and parameter setting. Oxford: Oxford University Press. 
Hill, Virginia. 2007a. Romanian adverbs and the pragmatic field. The Linguistic Review $24,61-86$.

Hill, Virginia. 2007b. Vocatives and the pragmatics-syntax interface. Lingua 117, 2077-105.

Hill, Virginia. 2014. Vocatives: How syntax meets with pragmatics. Leiden: Brill. Holmberg, Anders. 2016. The Syntax of Yes and No. Oxford: Oxford University Press. House, Juliane. 1989. Politeness in English and German: the functions of please and bitte. In Shoshana Blum-Kulka, Juliane House \& Gabriele Kasper (eds), Crosscultural Pragmatics: requests and apologies, 96-122. Norwood, NJ: Ablex.

ICE: International Corpus of English - Great Britain. http://www.ucl.ac.uk/englishusage/projects/ice-gb/index.htm [accessed 17 September 2019].

Jamieson, E. 2017. 'Negation' and CHECK moves in the Shetland dialect of Scots. Presented at NELS 48, University of Iceland.

Krifka, Manfred. 2001. For a structured meaning account of questions and answers. In Caroline Féry \& Wolfgang Sternefeld (eds), Audiatur Vox Sapentia: A festschrift for Arnim von Stechow, 287-319. Berlin: Akademie-Verlag.

Krifka, Manfred. 2014. Embedding illocutionary acts. In Tom Roeper \& Margaret Speas (eds), Recursion: Complexity in Cognition, 59-88. Heidelberg: Springer.

Krifka, Manfred. 2018. Questions in Commitment Spaces. Presented at GLOW 41 Semantics Workshop, Hungarian Academy of Sciences. http://www.zas.gwzberlin.de/180.html?\&L=0\%20order\%20by\%201000 (accessed 23 August 2018).

Krifka, Manfred. To appear. Layers of Assertive Clauses: Propositions, Judgements, Commitments, Acts. In Jutta M. Hartmann \& Angelika Wollstein (eds), Propositionale Argumente im Sprachvergleich: Theorie und Empirie 
[Propositional Arguments in Cross-Linguistic Research: Theoretical and Empirical Issues]. Tübingen: Narr.

Ladd, Robert. 1981. A first look at the semantics and pragmatics of negative questions and tag questions. Papers from the Seventeenth Regional Meeting of the Chicago Linguistic Society, 164-71.

Lahiri, Utpal. 2002. Questions and answers in embedded contexts. Oxford: Oxford University Press.

Laka, Itziar. 1990. Negation in syntax: on the nature of functional categories and projections. Ph.D. dissertation, MIT.

Lennon, John \& Paul McCartney. 1965. Help! London: Parlophone.

McCloskey, Jim. 2006. Questions and questioning in a local English. In Raffaella Zanuttini, Hector Campos, Elena Herburger \& Paul H. Portner (eds).

Crosslinguistic research in syntax and semantics: Negation, tense and clausal architecture, 87-126. Washington, DC: Georgetown University Press.

Merchant, Jason. 2001. The syntax of silence. Oxford: Oxford University Press.

Merchant, Jason. 2004. Fragments and ellipsis. Linguistics and Philosophy 27(6), 661738.

Munaro, Nicola \& Cecilia Poletto. 2004. Sentential particles and clausal typing in the Veneto dialects. ZAS Papers in Linguistics 35(2), 375-97.

Pittner, Karin. 2000. Position and interpretation of adjuncts: process, event and wieder 'again'. Approaching the grammar of adjuncts: ZAS Papers in Linguistics 17, 203-16.

Pittner, Karin. 2004. Where syntax and semantics meet: adverbial positions in the German middle field. In Jennifer R. Austin, Stefan Engelberg \& Gisa Rauh 
(eds), Adverbials: the interplay between meaning, context and syntactic structure, 253-87. Amsterdam: John Benjamins.

Portner, Paul. 2004. The semantics of imperatives within a theory of clause types. In Robert Young (ed.). Proceedings of SALT XIV, 235-52. Ithaca, NY: Cornell University.

Potsdam, Eric. 1996. Syntactic issues in the English Imperative. Ph.D. dissertation, University of California Santa Cruz.

Ritter, Elizabeth \& Martina Wiltschko. 2014. The composition of INFL. Natural Language and Linguistic Theory 32(4), 1331-86.

Van Rooy, Robert \& Marie Šafářová. 2003. On polar questions. Semantics and Linguistic Theory 13, 292-309.

Romero, Maribel \& Chung-hye Han. 2004. On negative "yes/no" questions. Linguistics and Philosophy 27(5), 609-58.

Rupp, Laura. 2003. The syntax of imperatives in English and Germanic: word order variation in the Minimalist framework. Basingstoke: Palgrave Macmillan.

Sadock, Jerrold. 1974. Toward a linguistic theory of speech acts. New York: Academic Press.

Sato, Shie. 2008. Use of "please" in American and New Zealand English. Journal of Pragmatics 40(7), 1249-78.

Schaar, John H. 1981. Legitimacy in the Modern State. New Brunswick, NJ: Transaction.

Schaden, Gerhard. 2010. Vocatives: a note on addressee management. University of Pennsylvania Working Papers in Linguistics 16(1), 176-85 
Searle, John R. 1979. Expression and meaning: studies in the theory of speech acts. Cambridge: Cambridge University Press.

Šimík, Radek. 2011. Introduction to the semantics of questions. Handout from the EGG Summer School 2011, České Budějovice, Czech Republic, 54 pp. http://egg.auf.net/11/abstracts/handouts/simik-w1a.pdf (accessed 23 August 2018).

Speas, Peggy \& Carol Tenny. 2003. Configurational properties of point of view roles. In Anna Maria DiSciullo (ed.), Asymmetry of Grammar. Volume 1: Syntax and Semantics, 315-44. Amsterdam: John Benjamins.

von Stechow, Arnim \& Thomas Ede Zimmerman. 1984. Term answers and contextual change. Linguistics 22, 3-40.

Stubbs, Michael. 1983. Discourse Analysis: The Sociolinguistic Analysis of Natural Language and Culture. Oxford: Blackwell.

Thoma, Sonja. 2016. Discourse particles and the syntax of discourse evidence from Miesbach Bavarian. Ph.D. dissertation, University of British Columbia.

University of Oxford, Bodleian Libraries. 2007. The British National Corpus, version 3 (BNC XML Edition). Distributed on behalf of the BNC Consortium. http://www.natcorp.ox.ac.uk/ [accessed 23 September 2019].

Weir, Andrew. 2014. Fragments and Clausal Ellipsis. Ph.D. dissertation, University of Massachusetts at Amherst.

Wichmann, Anne. 2004. The intonation of Please-requests: A corpus-based study. Journal of Pragmatics 36(9), 1521-49. DOI: http://dx.doi.org/10.1016/j.pragma.2004.03.003 
Wiltschko, Martina. 2014. The universal structure of categories: Towards a formal typology. Cambridge: Cambridge University Press.

Wiltschko, Martina \& Johannes Heim. 2016. The syntax of confirmationals: A neoperformative analysis. In Gunther Kaltenböck, Evelien Keizer \& Arne Lohmann (eds), Outside the clause: Form and function of extra-clausal constituents, 30540. Amsterdam: John Benjamins.

Woods, Rebecca. 2016a. Embedded inverted questions as embedded speech acts. In Kyeong-min Kim, Pocholo Umbal, Trevor Block, Queenie Chan, Tanie Cheng, Kelli Finney, Mara Katz, Sophie Nickel-Thompson \& Lisa Shorten (eds), Proceedings of the 33rd West Coast Conference on Formal Linguistics, 417-26. Somerville, MA: Cascadilla Proceedings Press.

Woods, Rebecca. 2016b. Investigating the syntax of speech acts: embedding illocutionary force. Ph.D. dissertation, University of York.

Woods, Rebecca \& Luis Vicente. 2017. Metacommunicative fragments as probes into the grammar of the speech act layer. Presented at Societas Linguistica Europaea 2017, Universität Zürich, Switzerland. 